\title{
POR QUE SÊNECA ESCREVEU EPÍSTOLAS?
}

\author{
INGEBORG BRAREN* \\ Faculdade de Filosofia, Letras e Ciências Humanas \\ da Universidade de São Paulo
}

\begin{abstract}
RESUMO: A epistolografia é considerada como um gênero particular da literatura. Presta-se aos mais diferentes desempenhos da linguagem escrita de acordo com as necessidades do homem em razão de sua característica específica: estabelecer comunicação entre pessoas ausentes, como uma das partes de um diálogo. Pode-se, no entanto, esquematizála. Sêneca serviu-se deste veículo em suas Epístolas Morais para apresentar os principais temas da filosofia estóica com o vigor de um discurso e de uma teoria renovados.
\end{abstract}

PALAVRAS-CHAVE: epistolografia; Sêneca; epistolas morais; estoicismo.

É por volta de 62 a 64 d.C. que Sêneca (Lucius Annaeus Seneca, 1 a.C.?-65 d.C.) escreve as Epistolas Morais. Depois de produzir tratados filosóficos, obras de cunho científico, consolações, tragédias e uma sátira, por que escrever agora epístolas? A primeira resposta é aparentemente fácil. Epístolas permitem oferecer doutrinação filosófica sem o necessário rigor de um plano de redação de um tratado filosófico. As epístolas se sucedem ao sabor das reflexões do momento. O conteúdo não necessita seguir uma ordenação global única. Diferentes assuntos podem ser tratados topicamente, desde que obedeçam à proposta pedagógica de ensinar o caminho para a sabedoria segundo um propósito determinado à doutrinação segundo os moldes do estoicismo. Uma segunda resposta pode ser obtida a partir do exame do modo como as epístolas foram escritas. A própria forma epistolar, com todas as suas implicações, é adequada às exigências de Sêneca.

Epístolas ou cartas têm características particulares. Por força da natureza do gênero, é obrigatório haver um emissor e um destinatário, ambos explícitos, mesmo que sejam anônimos ou coletivos, estabelecendo a situação epistolar. O circuito 
epistolográfico, que se desenvolve em uma relação eu-tu, obedece ao seguinte roteiro esquemático:

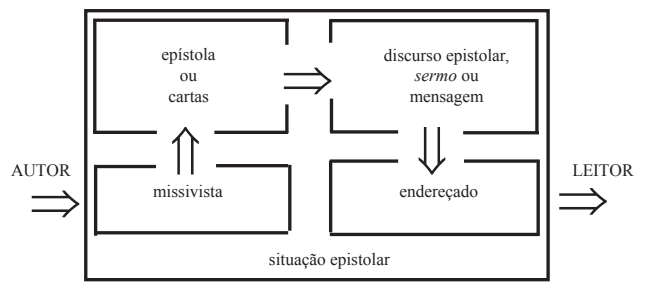

O autor, que é o sujeito empírico produtor do texto, pode ser único, impessoal, múltiplo ou anônimo. O missivista é o enunciador autorizado, explícito, que se materializa, cria tempo e espaço mediante um discurso. Do mesmo modo, o endereçado pode ser a figura explícita ou implícita do discurso. Quanto à distinção entre cartas e epístolas, desde longa data é um dos grandes problemas da Epistolografia. De maneira geral, convencionou-se considerar a carta como um escrito sem aspirações literárias, é consagrada ao destinatário em particular e, por isso mesmo, com a propriedade de aproximar pessoas distantes. A epístola, dirigida com intuitos literários, destina-se ao público em geral, ou pelo menos a um determinado público. Em 1923, A. Deissmann pretendeu precisar melhor essa distinção estabelecendo que a carta faz parte da vida e a epístola é testemunho de arte, assim a diferença entre carta e epístola é como entre natureza e arte (Thraede, 1970, p.13). Como há inúmeras possibilidades entre tais limites, fica extremamente vaga a classificação de toda a produção intermediária e o próprio Deissmann foi obrigado a admitir tipos mistos de cartas (Mischgattungen). Atualmente, de um modo muito amplo, Scarpat mantém a divisão tradicional em duas grandes categorias, cartas públicas (publicae) e cartas particulares (priuatae) (Scarpat, p. 499). Embora não satisfaça, aqui é suficiente, apenas a título de informação.

Do ponto de vista do conceito de Epistolografia na Antigüidade Clássica, não nos restou, infelizmente, uma teoria antiga específica e sistematizada sobre a epistolografia. Não contamos com muito mais do que o excursus de Demétrio sobre o estilo (Demetrius, 1927, p. 223-35); um texto de outro Demétrio (Tupoi epistolikoi, 219 - 3 15), observações esparsas de autores antigos, principalmente de Cícero e deduções obtidas a partir de como os antigos escreveram cartas e epístolas. Mais tarde, no século IV d.C., o retor Júlio Victor e o bizantino Josefos incluíram a Epistolografia no sistema da Retórica (Sykutris, 1931, col. 189). 
Se considerarmos a antiga definição de Artêmio, o editor das cartas de Aristóteles, de que carta é parte de um diálogo juntamente com referências de Cícero de que nelas o autor parece estar conversando com o amigo ausente, conloquia absentium (Cic. Fil. 2, 7, 4), teremos um bom ponto de partida, pois verifica-se que é muito comum o eu dirigir-se a um $t u$, como, na conversa, o locutor ao alocutado. Ademais, parecer dar a sensação de que o amigo está momentaneamente presente, praesentia absentium (Cic. Att. 9, 10, 1; Att. 12, 53; Fam. 15, 19, 1) é outro tópico freqüente na epistolografia.

$\mathrm{Na}$ verdade, o extraordinário de um texto epistolográfico são as marcas que estabelecem a ligação entre o próprio autor da carta e o missivista, o enunciador natural em primeira pessoa, seja em qualquer nível que ocorrer. Procuramos conhecer os sinais de identificação reveladores da personalidade, da ideologia ou da filosofia do eu que fala. No caso da Antigüidade Clássica, o texto é tudo ou quase tudo que temos. Fornece-nos o material de investigação que será tanto mais vivo quando melhor estabelecer a comunicação, principal requisito do discurso epistolográfico (quer a comunicação seja efetuada com o endereçado, quer seja com o leitor).

Embora Sêneca, em suas epístolas, tenha manifestado muito pouco de sua vida particular, é difícil examiná-las sem procurar informações históricas e vestígios de seu prestígio pessoal. O contexto tem a propriedade de emoldurar o discurso epistolográfico. Sabemos que o filósofo romano se engajou na vida cívica, atuou na política, respirou o ar do autoritarismo da dinastia júlio-claudiana, mas a chave de sua obra epistolográfica é o pensamento fiel aos princípios fundamentais da filosofia estóica, que abraçara desde sua juventude, que implica em pôr em prática a Seelenleitung.

De fato, quanto ao conteúdo, as epístolas oferecem o longo percurso sobre como deve ser o aprendizado da sabedoria. Aquele que se propõe empreendê-lo é proficiens. Tal aprendizado está fundamentado na moral estóica, no que tange à postura inquebrantável do homem diante do infortúnio, atitude esta proveniente do domínio da razão sobre as emoções (affectus).

Quanto à composição, as epístolas se estruturam sobre reflexões de vários temas, como o preço do tempo, o sentido da morte, o medo da morte, o valor da amizade, a disposição para suportar a pobreza e a riqueza, os sofrimentos, e outros assuntos que são tratados de acordo com o estoicismo. $\mathrm{O}$ método utilizado consiste em convencer Lucílio, o endereçado das epístolas, a dar o devido valor à virtude, a atribuir à razão o julgamento do bem e do conveniente e assegurar a calma interior.

Por exemplo, a "Epítola 1" é uma amostragem do tratamento que Sêneca confere a temas que ficam no perímetro circunscrito à vida prática e à vida interior. 
Ao lê-la, pode-se perguntar se apresenta coerência entre o postulado doutrinário e se evidencia as preocupações pessoais do filósofo, uma vez que Sêneca, retirado da vida política, escreve a seu amigo para demonstrar-lhe, com sensibilidade, que está cumprindo os deveres da verdadeira amizade.

Aliás o sentimento de philía é o mais comum na caracterização da situação epistolar, considerando tal situação como a moldura que circunscreve o texto epistolográfico. Sêneca é movido por genuíno interesse pela formação espiritual do endereçado. O discurso epistolográfico aproxima as pessoas e basicamente transmite a energia interior do seu ator.

Não se deve, entretanto, esquecer outro tópico importante fornecido pela epistolografia antiga que consiste em considerar que a finalidade de uma carta é ofertar algum brinde, tópico condensado por Cícero em poucas palavras: polliceri aliquid "ofertar algo" (Cic. Fam. 4, 13, 6; Fam. 6, 10, 6). De certa forma, é o que se encontrará na "Epístola 1". De fato, ela oferece parenese, além de máximas e sententiae dignas de meditação. Lembre-se que pertencem à função parenética, segundo Posidônio, a praeceptio, suasio, consolatio, exhortatio, inquisitio causarum e ethologia (Hadot, 1968, p. 8-9).

Verifica-se que a "Epístola 1" desempenha o papel de introdução de toda a obra epistolográfica que chegou aos nossos dias, exatamente porque configura uma proposta de vida, abordando um dos grandes problemas do homem: a passagem inexorável do tempo em relação à vida humana.

A construção desta epístola está modelada sobre oposições a partir das palavras iniciais: reuindica te tibi tempus. De um lado, está o ser humano em contexto temporal e, de outro, o conceito do tempo, em contexto pontual. Por esta razão a ênfase expressiva é conferida aos dois objetos diretos do verbo uindicare, te e tempus, um é a pessoa endereçada, que aqui pode ter dimensões universais, e o outro, o assunto da epístola, o tempo, cujo preço, inestimável e insubstituível, será demonstrado a partir da seguinte linha de raciocínio:

1. o tempo passado já não nos pertence, faz parte do domínio da morte;

2. todas as coisas não nos pertencem (omnia aliena sunt);

3. o único bem que possuímos, frágil e fugidio, é o momento presente;

4. todos os bens podem ser objeto de devolução, menos o tempo.

Estas reflexões, por seu conteúdo, configuram um verdadeiro brinde do filósofo ao leitor. Este é o aspecto da epistolografia de Sêneca que mais se evi- 
dencia nas epístolas, o oferecimento de um ensinamento ou de um pensamento elevado.

Mediante o interesse do conteúdo sublime, a epístola estabelece contato, faz ponte direta entre missivista e endereçado, cumpre sua pontual obrigação de comunicar, e oferece o resultado de uma maturação pessoal de Sêneca sobre uma questão inquietante para o homem, o valor do tempo, em contexto humano, reflexão esta que se converte em oferta de brinde para o endereçado e, por extensão, para os leitores da epístola.

\section{Nota}

* Professora Doutora de Língua e Literatura Latina do Programa de Pós-Graduação em Letras Clássicas e do Curso de Graduação da FFLCH-USP.

\section{REFERÊnCias Bibliográficas}

CANCIK, H. Untersuchungen zu Senecas Epistulae Morales. Hildesheim: G. Olms Verlag, 1967.

CIZEK, E. L'époque de Néron et ses controverses ideologiques. Leiden: E. J. Bril, 1972.

DEMETRIUS. On Style. Translated by W. R. Roberts. London: The Loeb Classical Library, 1927.

GRIMAL, P. Sénèque ou la conscience de l'empire. Paris: Les Belles Lettres, 1979.

HADOT, I. Seneca und die griechisch-römische Tradition der Seelenleitung. Berlin: W. de Gruyter, 1968.

LONGIN. Du sublime. Traduction, présentation et notes par J. Pigeaud. Paris: Petite Bibliothèque Rivages, 1991.

MAURACH, G. Der Bau von Senecas Epistulae Morales. Heidelberg: C. Winter, 1970.

SCARPAT. L'epistolografia. In: -. Introduzione allo Studio della Cultura Clasica I. Milano.

SYKUTRIS, J. Epistolographie. Paulys Wissowa Real Encyclopaedie. sup. 5, col. 185229, 1931.

TRAEDE, K. Grundzüge griechische-römischer Brieftopik. München: Zetemata, 1970. 
BRAREN, Ingeborg. Pourquoi Sénèque a écrit des épîtres?

RÉSUMÉ: L'épistolographie est considérée comme un genre spéciale de la littérature. Il est utilisé dans différents domaines du langage écrit selon les besoins de l'homme en raison de sa caractéristique spécifique: établir une communication entre personnes qui sont absentes comme une des parties d'un dialogue. Cependant, nous pouvons la shématiser. Sénèque a utilisé de ce véhicule aux Epistulae Morales pour présenter les principaux thèmes de la philosophie stoïque avec la vigueur d'un discours et d'une théorie rénovés.

MOTS-CLÉS: epistolographie; Sénèque; épîtres morales; stoïcisme. 